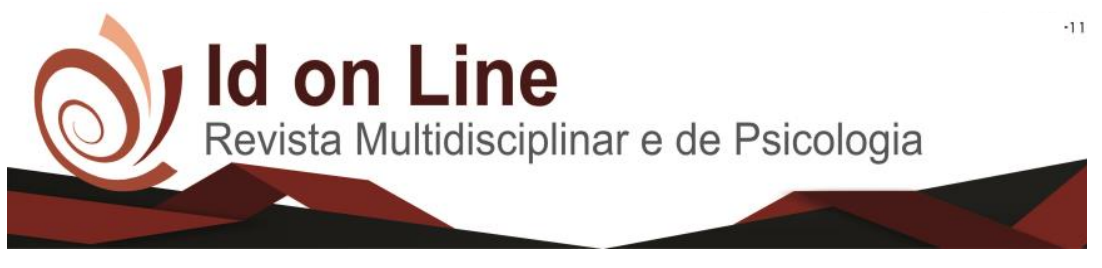

DOI: 10.14295/idonline.v13i46.2011

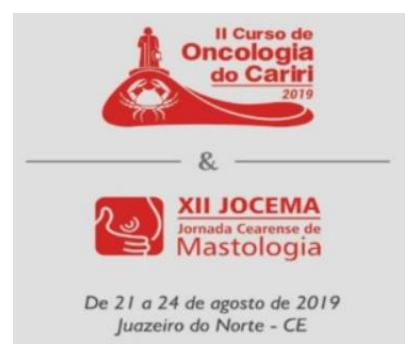

Resumo

\title{
TRATAMENTO DO CÂNCER DE MAMA NA GESTAÇÃO: UM DESAFIO PARA A MEDICINA
}

\author{
Paula Gabriella de Sousa Araújo ${ }^{1}$; Helen Fernanda de Oliveira Sousa ${ }^{1}$
}

Introdução: Conceitualmente, o câncer de mama está relacionado com a gravidez quando é diagnosticado durante o período gestacional ou até um ano do pós-parto. Nessa perspectiva, o conflito entre morte e nascimento constitui um verdadeiro paradigma para os profissionais médicos, principalmente em relação a escolha terapêutica, já que há riscos letais para a mãe e para o feto. Dentre as opções estão: quimioterapia, radioterapia e cirurgia, porém a decisão final necessita de um consenso entre oncologista, neonatologista e obstetra, além da permissão da gestante. Com isso, o tratamento torna-se mais efetivo e seguro para mãe e filho (a). Objetivo: O manejo da gestante com câncer de mama ainda gera muitas dúvidas e divergências na área médica. Dessa forma, é necessário analisar cada caso de forma singular, ponderando os benefícios e malefícios das propostas terapêuticas, tendo como direcionamento a avaliação da idade gestacional e estadiamento da doença. Além do controle do câncer, é importante que a intervenção não traga prejuízos imediatos, tampouco a longo prazo ao feto. Métodos: Foi elaborado a partir da revisão de literatura obtida através de análises de artigos científicos que tem como base de dados o Google Acadêmico e SCIELO. Os principais descritores utilizados foram câncer de mama, câncer de mama durante a gestação, quimioterapia e radioterapia na gestação. Resultados: A proposta do tratamento do câncer de mama em mulheres grávidas é semelhante à de mulheres não grávidas, isto é, obter o controle local da doença e evitar possíveis metástases. A escolha equivocada do manejo terapêutico pode acarretar em danos graves e irreversíveis, dessa forma a assistência integral e individualizada da gestante é o diferencial para obter-se resultados satisfatórios. Conclusão: O câncer de mama por ser o tipo de neoplasia maligna mais frequente durante o período gestacional ainda levanta muitos questionamentos em relação ao tipo de tratamento mais efetivo e seguro tanto para a mãe quanto para o feto. A cirurgia, sempre que possível, é a opção mais viável de tratamento nessas mulheres, porém a grande maioria ainda recebe indicação de quimioterapia sistêmica, segura e eficaz no segundo e terceiro trimestres da gestação. Por fim, o uso da radioterapia é preferível após o parto. Nessa perspectiva, as decisões terapêuticas devem respeitar os princípios científicos, éticos, legais e religiosos.

Palavras-Chave: Câncer de mama. Quimioterapia. Gravidez.

1 Acadêmica no curso de medicina Faculdade de Medicina Estácio de Juazeiro do Norte. 


\section{Referências}

BARROS, Renata Rodrigues; GANDA, Ingrid Shweter. CÂNCER DE MAMA DURANTE A GESTAÇÃO. OS DESAFIOS E AVANÇOS NO TRATAMENTO. Semana de Pesquisa da Universidade Tiradentes-SEMPESq, n. 16, 2014.

CARVALHO, Solange Maria Torchia et al. Câncer de mama na gestação: relato de casos. Rev Bras Mastol, v. 20, n. 2, p. 86-8, 2010.

KETTELHUT, Juliana Do Carmo; MODENA, Marco Antônio Bittencourt. Câncer de mama e gestação. Revista da Faculdade de Ciências Médicas de Sorocaba, v. 10, n. 4, p. 1-4, 2008.

MENDONÇA, Gabriel Soares et al. Câncer de mama e gestação: Relato de caso e revisão de literatura. Revista Científica da FMC, v. 8, n. 2, p. 13-15, 2013.

MONTEIRO, Denise Leite Maia et al. Câncer de mama na gravidez e quimioterapia: revisão sistemática. Revista da Associação Médica Brasileira, v. 59, n. 2, p. 174-180, 2013.

MONTEIRO, Denise LM et al. Câncer de mama na gravidez: diagnóstico e tratamento. Revista Hospital Universitário Pedro Ernesto, v. 13, n. 3, 2014. DE OLIVEIRA, Claudia; CIPRIANO, Pâmella. Gestação e câncer de mama: proposta de guia de orientações. Fisioterapia Brasil, v. 16, n. 3, p. 248-254, 2016.

SCHÜNEMANN JR, Eduardo et al. Radioterapia e quimioterapia no tratamento do câncer durante a gestação-revisão de literatura. Revista Brasileira de Cancerologia, v. 53, n. 1, p. 41-46, 2007. 